\title{
LA MUERTE APARENTE EN LA OBRA POÉTICA DE ROSAMEL DEL VALLE
}

\section{THE APPARENT DEATH IN ROSAMEL DEL VALLE'S POETIC WORK}

\author{
Sergio Pizarro Roberts \\ Doctor (C) Literatura Hispanoamericana Contemporánea. \\ Universidad de Playa Ancha, Chile. \\ sergioto.pizarro@gmail.com
}

\begin{abstract}
Resumen: Como consecuencia de una lectura global y diacrónica de la obra poética de Rosamel del Valle se precisarán los aspectos relevantes que, a nuestro juicio, le dan valor estético a su propuesta metafísica. Se propondrá, inicialmente, la analogía de su trabajo poético con las principales doctrinas y creencias palingenésicas, resultado de lo cual se comprobará una acepción resignificada de la muerte. Ello, en virtud de la ascendencia órfica de su estética escatológica que representa la indefinida circulación del sujeto poético rosameliano en un mecanismo de rotación trascendente (catábasis y anábasis) cuya decodificación simbólica desliza la auspiciosa idea, dentro una cosmovisión vitalista y veladamente soteriológica, de que la muerte realmente no existe.
\end{abstract}

Palabras claves: palingenesia, catábasis, anábasis, necropoética, poesía chilena.

Abstract: As a result of a complete and diachronic reading of the poetic work written by Rosamel del Valle, the relevant aspects that, from our own perspective, give aesthetic value to his metaphysical proposal, will be addressed. Specifically, the analogy of his poetry with the main doctrines and beliefs of Palingenesis, resulting in a verification of a resignified meaning of death. This, considering the orphic origin of his eschatological aesthetics that represents the indefinite circulation of the poetic subject in Rosamel del Valle's work, in a mechanism of transcendent rotation (katabasis and anabasis) of which its symbolic decoding hints at the auspicious idea, within a vitalist and veiled soteriological vision, that death does not actually exist.

Key words: palingenesia, katabasis, anabasis, necropoetics, Chilean poetry.

Recibido: $11-08-20$

Aceptado: 09-11-20

La imaginación humana, en su afanosa colonización de la invisibilidad, le ha brindado a la muerte, a lo largo de la historia, un sinnúmero de significados mediante relatos empíricamente incomprobables y las creencias palingenésicas son una de las varias 
formas con las que se ha pretendido dar una explicación al misterio tanatológico. No logran estas creencias, sin embargo, la unanimidad en lo que concierne a su acepción. José Ferrater Mora, por ejemplo, en su Diccionario de Filosofía, enfatiza lo medular del concepto palingenesia (palin, de nuevo; genesis, nacer) mediante las nociones de "renovación, regeneración o renacimiento" (360). Agrega, a continuación, que se llama palingenesia "a toda reaparición periódica de los mismos hechos, de las mismas vidas o de las mismas almas" (360), una especie de eterno retorno de lo mismo. Por otra parte, el filósofo francés Vladimir Jankélévitch admite el dilema del término al reconocer, sobre la base etimológica común de un nacer de nuevo, dos posibles interpretaciones: o se trata del nacimiento sucesivo del mismo ser, caso en el cual la muerte se constituye en una pausa interrumpida por una cadena de renacimientos o bien, "el vacío abierto de la muerte se interpone como un corte irreductible entre la nueva vida y la antigua" (323), en donde, sobre el sustrato base de una esencia común y permanente, cada nacimiento supone el surgimiento de otro ser completamente nuevo en relación al anterior extinto.

Ferrater Mora, entonces, aplica un criterio restrictivo al asimilar la palingenesia a la renovación de lo mismo y Jankélévitch, en cambio, reconoce una mayor amplitud del término cuyo carácter genérico incluiría otras posibles alternativas de regeneración en las que tras la muerte surge un ser transformado, situación que se da, vía ejemplo, en la antigua doctrina griega de los misterios órficos (transmigración de las almas), y que influye en la cosmología pitagórica (siglo VI a.C.) y en la teoría de la reminiscencia de Platón (siglo V a.C.), o en el caso de otras creencias religiosas como la peregrinación de las almas postulada por el Budismo o contenida en los textos hinduistas de los Upanishad (siglo IX al $\mathrm{V}$ a.C.). Estas doctrinas y creencias, que en un principio provocan el vértigo metafísico ante tanta opción de trascendencia, serán latamente analizadas en el presente trabajo en orden a demostrar su cercanía o distanciamiento con la poética escatológica del escritor chileno Rosamel del Valle (1901-1965) y proponer, en consecuencia, una hipótesis de lectura que permita dilucidar dentro de su obra una eventual resignificación de la muerte.

El año 1926 el poeta de Curacaví publica Mirador, una obra poética escrita en verso y dividida en 19 secciones, en cuyo texto la muerte no es nombrada ni se perfilan 
inquietudes metafísicas ${ }^{1}$. Su importancia indiscutible radica en que, bajo el halo creacionista de Vicente Huidobro, el hablante rosameliano despliega un novedoso tono vanguardista a través del carácter urbano de sus versos y del tratamiento yuxtapuesto en tiempo y espacio de realidades antagónicas. Sin embargo, dicha tonalidad adopta matices que lo alejan de su precursor huidobriano cuando el hablante no impregna el discurso con los decibeles de una voz estentórea, tan característica, además, en sus coetáneos Pablo Neruda y Pablo de Rokha. Acusa, por ende, la influencia complementaria de una segunda tendencia que lo lleva a desarrollar un estilo intimista más conectado consigo mismo. En efecto, explica Juan Villegas que al entrar el grupo del 25 en la escena literaria (integrado por Rosamel del Valle, Juvencio Valle, Humberto Díaz Casanueva y Pablo Neruda), dominaban en Chile tres tendencias: una representada por Huidobro, de orientación vanguardista, "[1]a segunda [que] correspondía a poetas como Pedro Prado, Juan Guzmán Cruchaga y Ángel Cruchaga Santa María de inclinación intimista y, en algunos casos religiosa y panteísta" (57), y una tercera representada por Pablo de Rokha, de orientación social. Como consecuencia de la segunda tendencia, el sujeto rosameliano más que interactuar hacia afuera con otros receptores del discurso, dirige su mirada hacia el interior de sí mismo².

El arte poética de la videncia intimista continuará su desarrollo en el siguiente libro del autor, País blanco y negro (1929), en textos como el que sigue: "[m]e rodean cosas y sucesos pequeños. Mis ojos transforman estas cosas y estos sucesos sin el sentido que representan. Y es que mis ojos viven en su labor de sorpresa libre y sin derrota" (I 57). Se comprueba la tonalidad menor en cosas y sucesos pequeños que evitan la grandilocuencia desplegada por sus coetáneos; un cambio de escenario que tiene por efecto disminuir la intensidad semántica de la imagen cuando en otras secciones del libro se constata la sustitución de términos claves como el de faro por lámpara o el de zócalos y planicies por habitación (I 58-60). Al alero de esta proyección estética encontramos una tímida mención

\footnotetext{
${ }^{1}$ Las citas en este trabajo a las obras poéticas de Rosamel del Valle serán hechas a la compilación, en dos tomos, efectuada el año 2000 por Leonardo Sanhueza con J.C. Sáez Editor.

${ }^{2}$ El crítico René Olivares, en su extensa monografía crítica sobre la obra de Rosamel del Valle, señala que "si en la caracterización romántica del poeta, y que recogerá posteriormente el modernismo, existía una tendencia a verlo como un ser sobre el resto de los seres humanos, hay en el poeta chileno [del Valle] una inversión. No es el hombre-dios o el pequeño Dios de Huidobro, [...] no hay detrás de esta idea una valoración que indique que el poeta por ello sea mejor o que le otorgue ciertas garantías sobre el resto de las personas [...] el poeta es más bien el hombre conectado consigo mismo" (Mito y modernidad... 127).
} 
primeriza de la muerte al interior de los 10 poemas en prosa que configuran País blanco y negro, y que acusa una incipiente inquietud metafísica: "[e]l corazón es lo primero que se desinfla en la muerte y apenas sí se queda un instante vibrando sobre el cabello de las arenas. Sobre este suceso el vacío permanece como si por sus cejas hubiera intentado pasar el viento" (I 59).

El año 1939 es una fecha decisiva para el mundo contemporáneo al declararse la Segunda Guerra Mundial, y coincide con la tercera entrega de Rosamel del Valle, un contundente proyecto titulado Poesía, dividido en 5 secciones escritas en verso. Esta década, en que estalla la Guerra Civil Española (1936-1939) y se desata la conflagración mundial (1939-1945), atestigua las consecuencias estéticas que conlleva la presencia relevante de la muerte en estados de guerra, ya que domina el paisaje y activa una mirada exasperada hacia la carga semántica de esa palabra tan evitada. La muerte adquiere una trágica intensificación durante los procesos bélicos que modifica la visión más neutral, o resignada si se prefiere, que se proyecta en tiempos de paz. Rosamel del Valle no escapa a esa intensificación al comprobarse, a diferencia de lo que ocurre en sus obras anteriores, un mayor protagonismo temático de la muerte y sus acepciones afines en el texto poético. Precisamente, en la segunda parte de Poesía, titulada "Cuerpo central”, 13 de los 20 poemas que conforman dicha sección la mencionan. Aún más, todos los poemas de la tercera parte, "La mano encendida", aluden a ella e incluso, por primera vez en la obra rosameliana, cuatro poemas de esta tercera sección se intitulan con su mención (“Celebración de la muerte” y "La muerte pública", por ejemplo).

En este periodo se confirma el inédito compromiso político del poeta mediante su adhesión a la causa republicana española y los poemas destinados al efecto son, coincidentemente, aquellos en que la muerte tiene participación preponderante como los que se titulan "Paisaje del poeta asesinado" (escrito a la memoria de Federico García Lorca), "España, muerte devuelta" y "Soldado de Madrid”, y que contienen versos como el siguiente: "Oh larga muerte necesaria para vivir y viceversa" (I 135) o en otro lugar, donde el hablante espeta "[s]omos los muertos" (I 131), configurándose representaciones tanatológicas inauditas.

Coherente con esa misma línea de compromiso, en el homenaje Madre España de 1937 que, a petición de la filósofa española María Zambrano, suscriben varios poetas 
chilenos (Winett de Rokha, Vicente Huidobro, Pablo de Rokha, Pablo Neruda, Braulio Arenas, Juvencio Valle y Carlos de Rokha, entre otros), Rosamel del Valle incluye el poema titulado "Mensaje en el oído del Océano Pacífico", dedicado a Rafael Alberti, y que contempla los siguientes versos: “Allá lejos la muerte en alegría, la muerte en esta alegría, la muerte sola. [...] La vida tiembla desde albas de muerte hasta noches de puños sonámbulos [...] Desde el foso donde nadan sonrientes los milicianos asesinados" (15). Los milicianos muertos están lógicamente impedidos para nadar sonrientes en un foso y, sin embargo, en el poema están oximorónicamente vivos con lo cual se provoca una alteración semántica de los términos opuestos. La cruda realidad confrontacional de la guerra, entonces, es subjetivizada en un lenguaje que cristaliza las alteraciones significativas de las palabras removidas en sus acepciones tradicionales y provoca un desplazamiento de la carga semántica de la muerte.

La consecuente intensidad metafísica del discurso poético rosameliano se plasma en textos claves, desde la perspectiva de esta investigación, como el poema "Inscripción en la puerta del tiempo" (último de la tercera sección de Poesía), del cual rescato los siguientes fragmentos:

Nuestra esencia viene de la tiniebla rasgada [...]

Construida de ángeles ciegos y temblores y de la infinita ola Amante de lo terrestre sin límite y del olvido.

Pero una transparente llama sigue a la sangre desde el tiempo

De un calor indestructible, de una voz dormida a lo lejos. [...] //

Poder volver un día al latido lejano, a la sumergida

Ola sin llanto donde el corazón bebía su fuego en la copa

Nocturna y palpitante, como el pez ama su agua. [...]//

Sangre y ceguera y necesidad del abismo donde el ser perece

Entre ángeles y demonios todavía, entre ritos, [...]

Siempre, más que a imagen de la vida, a semejanza de la muerte. //

Amenazada existencia tan cálida de sonidos, de movimiento

Sin fin, donde el sueño de las cosas nos oye día y noche, Donde el hombre nos oye, donde nosotros nos oímos y donde

Lo que no es nuestra esencia nos oye y nos mira. [...]//

¿Qué se le oye decir? ¿Qué puertas abre? ¿Qué estremecimiento

Conduce? ¿Qué despierta en la lengua sin ojos de los muertos? (I 139140). 
El hablante evoca la vida como una esencia que surge a través de la rasgadura de las tinieblas, es decir, amplía los márgenes de la existencia, antes del nacimiento y después de la muerte. El texto, a su vez, supone la posibilidad de un tránsito cuando dicha esencia proviene de la referida tiniebla y vuelve un día a la sumergida ola, donde el ser perece. Una puerta del tiempo, según el título del poema, que es necesario cruzar para constatar el movimiento sin fin de la existencia, en un giro textual que comunica la posibilidad de una experiencia trascendente. Se trata de un texto en que el hablante no cruza el umbral de la puerta simbólica sino que anuncia, apenas, la potencialidad del cruce; un texto que, según reza el último verso de la transcripción, se pregunta qué despertará, más allá del cruce, con la voz de los muertos.

El título "El corazón sumergido", de la cuarta parte y siguiente del libro Poesía, leído en el contexto de los 50 poemas que conforman dicha sección, es decidor, ya que alude a un hablante que, a diferencia del poema "Inscripción...", antes citado, atraviesa finalmente el umbral simbólico de la puerta e ingresa a la muerte (se sumerge en ella) para emitir su discurso desde dicho lugar de enunciación, constituyéndose en un original sujeto poético escatológico. El hablante celebra la experiencia en los poemas "Danzas” y "Dios". En el primero, cuando señala: “[p]or fin conozco las cálidas espumas de sombra / que venían en mí mismo en continuado perecer. / [...] un movimiento de inextinguible / luz envuelta entre cielo y tierra" (I 147), y en el segundo: “[q]ué escala mágica conduce y devuelve entre músicas / [...] y penetrante calor sin muerte / en enloquecido y continuo pasar" (I 147). Estos versos que atestiguan el tránsito de ida y vuelta hacia la muerte suponen una concepción palingenésica de la existencia con señales textuales que aluden a 'movimientos de inextinguible luz entre cielo y tierra' o un 'continuo pasar sin muerte', y deben leerse en concordancia isotópica con referentes análogos contenidos en otros poemas del conjunto (escala, viajero, pasajero del tiempo, voces viajeras, lámparas errantes etc.).

Según Jankélévitch:

[L]a filosofía de la palingenesia, para conjurar el espectro de lo irrevocable, imagina un intercambio y, en cierto modo, idas y venidas continuas entre la vida y la muerte; las almas cruzan y vuelven a cruzar ese umbral fatídico que ya no tiene nada de fatídico, y circulan libremente de un mundo a otro. Se entra en el país de los muertos como en una noria y se sale de la misma manera (320). 
El renacer, después de haber transitado por la muerte, se constata en los versos del poema "Nueva obscuridad", de la misma sección "El corazón sumergido": "[á]brete espesa red y cemento nocturno, / con permanecer de ola detrás del océano / e inaccesible dicha de las lámparas que pasan" (I 152) y en el poema "Escalas": "[s]alir, salir conducido a través de las puertas / sin fin y obstinados descansos donde la sombra / cesa de perecer" (I 153). Lámparas que pasan a través de nuevas obscuridades y sombras trascendentes que dejan de morir dan indicios de un renacimiento que vuelve a aparecer en el poema "Aire libre": "[y] ahora, oh muerte oculta y saciada por fin, / déjame entrar en el aire mental renacido / [...] déjame tocar la próxima atmósfera" (I 154). Estamos definitivamente ante un hablante que se constituye en sujeto poético escatológico ya que le habla a la muerte desde el intersticio que se abre entre una vida y otra, y le solicita la continuación del proceso de rotación cíclica. En efecto, en el siguiente poema "Zona blanca" el hablante, ya renacido, comunica su nuevo entusiasmo vital: "[d]espierto y una boca blanca exhala su vapor / por la atmósfera y el tiempo vencido [...] / despierto por fin y entre puertas de vidrio y voces" (I 155). Y mediante el elocuente título de "Corazón flotante", dicho hablante insiste: "[o]h maravillosa copa y vértigo a la orilla / de las sienes obscuras donde se abre / mi existencia contenida / [...] qué noche / de muertos huye si giras" (I 155). Del corazón sumergido que enunciaba el título de la sección nos hemos trasladado hasta un corazón flotante, tránsito que representa el descenso y ascenso trascendente del sujeto poético que, finalmente, se instituye como corazón universal, cuando invita en el respectivo poema: "[p]asad iluminados y sin sueño, pasad sonámbulos, / [...] pasad muerte en tinieblas y viaje inseguro" (I 156), y que transmite la sensación de un hablante relativamente empoderado en el proceso palingenésico concebido en el texto.

En este punto es necesario aclarar que Rosamel del Valle no tiene la exclusividad en el tratamiento poético de un sujeto escatológico. Hablantes cuyo locus de enunciación se sitúa en la muerte los encontramos en Vicente Huidobro, en Pablo Neruda, en Gabriela Mistral e incluso antes, en ciertos rasgos panteístas de la obra de Pedro Prado. Sin embargo, la novedad que ofrece la obra poética rosameliana radica en que, al resignificar heterodoxamente a la muerte con una propuesta estética que se aleja de la tradición chilena 
cristiana, lo hace en clave simbólica mediante las figuras de catábasis y anábasis, un mecanismo de rotación trascendente que, en mi parecer, debe su fuente al orfismo griego.

Ferrater Mora señala que la doctrina de los misterios órficos se basa en el mito de Dioniso, hijo de Zeus y Perséfone, y que al tenor del relato mítico

fue devorado por los Titanes, salvo el corazón, que fue dado a Zeus por Atenea. Destruidos los Titanes por los rayos de Zeus, emergieron de sus cenizas los hombres, cuya existencia aloja dentro de sí el mal de los Titanes y el bien de Dioniso. Dioniso nació de nuevo del corazón tragado por Zeus; esta resurrección es fundamental en la doctrina órfica y en sus ritos; por un lado, llevó a la creencia de la transmigración; por el otro a la abstinencia de la carne (340).

Como señala la cita, la resurrección del dios sentó las bases de la creencia órfica de la transmigración de las almas, una doctrina palingenésica en virtud de la cual, después de la muerte, la vida no termina sino que continúa en ciclos sucesivos donde el alma migra o transita a través de cuerpos que pueden ser de diversa índole, incluso animales, lo que explica la abstinencia de la carne allí señalada. Esta doctrina de índole soteriológica, que pregona la salvación del hombre mediando la inmortalidad del alma, sustenta el pensamiento religioso de Occidente, ya que influye decisivamente en dos pensadores griegos: en Pitágoras, que funda su secta exiliado en Crotona al sur de Italia, y en Platón, cuya instauración idealista del alma servirá de base para la distinción judía y cristiana de un más allá sagrado (ideal) y este mundo profano.

En las creencias pitagóricas, al tenor de la traducción del filólogo español Alberto Bernabé, el problema de la salvación era fundamental y no es de extrañar que se desarrollara una elaborada teoría del alma, aumentada con relación a los himnos órficos, por la relación del hombre con el cosmos numérico que propugnaba. Explica Bernabé algunas ideas básicas del pitagorismo:

El parentesco entre todos los seres animados del cosmos implica un alma inmortal, que por medio de determinadas observancias rituales -emparentadas con las practicadas por los órficos- buscaban tras sucesivas encarnaciones una asimilación a lo divino. El alma es, por tanto, una chispa del alma divina y universal contaminada en su asociación con la materia corporal (77). 
Se concluye de ambas citas que, según estas doctrinas, habría un alma universal de la cual el ser humano se separa al nacer para iniciar una cadena sucesiva de renacimientos, en donde ese fragmento diminuto de alma que nos constituye, transmigra (al parecer indefinidamente) a través de varios cuerpos para garantizar la circulación de la vida y evitar un estancamiento que implicaría la muerte. Se menciona una 'asimilación a lo divino' pero no se tiene certeza sobre si esta creencia postula un reingreso definitivo al alma original y universal de la cual se desprendió, ya que según Bernabé:

[C]uando tratamos de penetrar más allá de estos principios generales y vagos e intentamos profundizar en el concepto pitagórico sobre la naturaleza del alma, nos encontramos con que ya en la antigüedad había diferentes explicaciones sobre la cuestión, y con que los testimonios no coinciden entre sí en este punto (77).

Consultada otra fuente, como el poema épico Metamorfosis, del latino Ovidio (43 a.C.-18 d.C.) - un referente literario crucial para Rosamel del Valle-, comprobaremos esta falta de certeza cuando el poeta pone en boca de Pitágoras la siguiente explicación de su doctrina, sin aclarar acerca de la posible cesación del ciclo de renacimientos y su posterior integración divina:

[L]as almas no mueren, y siempre, tras abandonar su sede anterior, son acogidas en nuevas moradas en las que viven y habitan. [...] Todo se transforma, nada perece. El espíritu anda errante, va de allá para acá y de acá para allá y se adueña de cualquier cuerpo, y de los animales pasa a los cuerpos humanos y de nosotros a los animales, y nunca muere. [...] Todo fluye, todas las cosas reciben formas inestables. [...] Y, creedme, en todo el universo no hay nada que perezca, sino que todo cambia y renueva su forma; llamamos nacer a empezar a ser algo distinto de lo que se era antes, y morir a dejar de ser eso mismo. Aunque eso se traslade aquí y esto allí, la suma de todo permanece igual (450-453, énfasis agregado).

La estela de las doctrinas órficas se aprecia en la influencia que tuvieron en el Fedón, de Platón:

Es antigua la creencia mencionada de que las almas van de aquí a la morada de Hades y de allá vienen acá y renacen a la vida después de la 
muerte. Siendo esto así, dado que los vivos nacen de los muertos ¿qué otra cosa puede ocurrir sino que nuestras almas están allá en el entretanto? (104).

La doctrina platónica de la metempsicosis es heredera del orfismo por cuanto postula la continuidad palingenésica de las almas en ultratumba pero se aleja en dos sentidos. Por una parte, después de la muerte el alma regresa al Hades, en compás de espera ante un nuevo nacimiento, y no al alma universal de la cual se desprendió originalmente. En segundo lugar, y seguramente por no producirse esa fusión intermitente con el alma universal, se transmiten algunos caracteres síquicos y físicos del fallecido hacia el nuevo ser que nace (con ello Platón justifica las semejanzas entre padres e hijos y plantea su teoría de la reminiscencia, que afecta directamente al logos, al sostener "que nuestro conocimiento no es sino un recuerdo" (108). De lo anterior se desprende que, a diferencia de las doctrinas órfico-pitagóricas anteriores, en las que se pierde la individualidad en el trance de muerte, la metempsicosis considera la continuidad relativa de la individualidad mediante la transmisión parcial de rasgos físicos y síquicos (no es una continuidad total de la individualidad como se da en el caso de la resurrección cristiana).

Corresponde preguntarse a esta altura de la investigación qué tan cercana se encuentra la poética escatológica de Rosamel del Valle con respecto a los textos mistéricos, en consideración a que su obra Poesía, hasta la cuarta sección, contiene un hablante que recién atisba a través de la puerta del tiempo y la cruza tímidamente para iniciar una incipiente experiencia órfica, en donde se aprecia uno, o a lo más, dos ciclos de catábasis y anábasis, y que volvemos a confirmar en los siguientes versos del poema "Himno del corazón heroico": "[p]or fin al aire libre y la voluntad del cielo / en amor y compañía de coros y penetrante / resurrección del tiempo y del rigor fortalecido" (I 162), que acuña un notorio temple optimista y celebratorio del trance. Una segunda interrogante que surge es si en este ciclo de renacimientos el sujeto escatológico rosameliano mantiene su individualidad o, según la tradición órfico-pitagórica, la pierde en cada una de las metamorfosis, y una tercera duda, consecuencia de la anterior, es la que indaga acerca de la eventual mantención o pérdida del conocimiento en el trance mortal de dicho hablante.

En orden a aclarar estas dudas, y dentro de una coherente progresión metafísica que avanza conforme al desarrollo de la obra, se constata que el hablante ofrece en la quinta y 
última sección de Poesía, titulada "El hombre devorado", señales más evidentes que ayudan a dilucidarlas. Ante la primera interrogante se puede sostener que, conforme a todas las citas antes rescatadas de Poesía y al tenor de los versos que siguen, la poética escatológica rosameliana abreva del pensamiento palingenésico del orfismo griego: "[c]uántas lámparas de terror crecieron un día oh, rayo / de mis huesos sumergidos en la oscuridad, en la sangre / misma del secreto sin piel y sin salida y sin voz" (I 168). Atendida la segunda interrogante, se comprueba un alejamiento de esa fuente órfico-pitagórica (y una adscripción relativa al contexto cultural cristiano en el que nace su obra) con un hablante que mantiene la individualidad cuando sostiene: "[p]asión de perecer en atmósferas cálidas o en la voz de uno mismo / recuperada de pronto entre la luz terrestre" (I 171, énfasis mío). Finalmente, ante la tercera interrogante, y en consideración a que el hablante mantiene su individualidad, en el último poema de la cuarta sección, titulado "Alegoría", se capta un indicio aclarador:

Visitante y destino encadenado a las olas Del rumoroso océano de la memoria y al paso

De los obscuros movimientos de la arena Nocturna y renovada infinitamente desde la sombra $[\ldots]$

Mi existencia es tu sed abandonada [...]

Del hombre que lo sigue hasta el fondo

De la memoria estremecida en la muerte (I 162).

En estos versos, que supone una memoria 'renovada infinitamente desde la sombra', se da a entender que en cada ciclo de renacimiento se produce la purificación que requiere la catábasis para que continúe en anábasis; una limpieza del logos que borra, no totalmente, el conocimiento previo, ya que la memoria no es eliminada sino que 'estremecida en la muerte'. Se percibe un hablante reminiscente que en otro poema declama: “[m]emoria mía, amada tiniebla mía, corona de lámparas degolladas / ¿De qué cielo regresas, de qué agua despiertas?" (I 167, énfasis agregado).

La siguiente obra poética que publica el autor en 1944 es el célebre Orfeo, escrita en verso y dividida en 10 secciones. En esta obra se hace patente la progresión metafísica a la que hice alusión anteriormente, por cuanto si en Poesía el hablante escatológico mantenía su individualidad a través y después del trance mortal, aquí se reafirma dicha continuidad al asimilarse con Orfeo, el mítico personaje que desciende al Hades afanado en recuperar a su 
esposa Eurídice mediante la seducción de los dioses del inframundo con su hermoso cantar, para regresar posteriormente a la vida sin éxito en su empresa. A diferencia del impreciso hablante innominado de Poesía aquí es Orfeo quien desciende y asciende desde la muerte sin perder su individualidad en el trance. Al símbolo de la puerta, en esta publicación se agrega el del viaje. "Bienvenido viajero devorado que te asomas" (I 175) reza el tercer verso de la obra, en directa relación con el título "El hombre devorado" de la quinta sección de la obra anterior. Y más adelante, "El descenso, nada más que el descenso por vertientes de fuego / [...] la eternidad en un puente melodioso" (I 177), en donde se representa la continuación del auspicioso proceso de rotación metafísica a través de un puente melodioso por el que atraviesa el viajero hacia la eternidad. 'El hombre eterno' al que se alude más adelante, no es sino Orfeo que nos vaticina: "vuestra muerte es la obscuridad reducida" (I 181), en un incipiente giro hacia un discurso soteriológico que propende a la salvación en la medida en que se reduce la muerte mediante un hablante definitivamente empoderado en el proceso palingenésico de catábasis y anábasis cuando instruye: "oh abismo de magia, abrid las puertas selladas, / el ojo por donde debo volver otra vez al cuerpo de la tierra” (I 190). Y en una clara cosmovisión vitalista, los últimos versos del poemario apuntan: "el hechizo está naciendo siempre, [...] / y si todo recomienza, todo debe seguir. / Yo soy el Tiempo [...] / Yo soy el amor y sobre todo la Vida, pues soy el que abraza y el que sepulta. Y para que todo siga, Eurídice es mi muerte" (I 201), versos notoriamente propensos hacia una reducción semántica de la muerte y cuyo léxico viene prestado desde la simbología cristiana para ser decodificado en el poema.

La obra de Rosamel del Valle, al momento de la publicación de sus trabajos, concitó una no despreciable recepción crítica, mayoritariamente reseñas periodísticas, nacionales e internacionales. Paulatinamente, a inicios del siglo XXI, se ha ido acumulando una bibliografía crítica, principalmente chilena, de mayor vuelo teórico, donde alcanzo a distinguir dos tendencias principales, complementarias entre sí. Una primera que enfatiza los aspectos metapoéticos de la urdimbre textual rosameliana y que tiende a comprenderla, al alero de una simbología metafísica, como una inmersión hacia el interior insondable del ser humano. Y otra, más actual en sus intereses, que prioriza los aspectos urbanos de dicha obra con el objeto de resaltar a un sujeto poético que se contrapone estéticamente al sujeto moderno. Ejemplos de la primera tendencia se perciben en los estudios de Alan Schweitzer: 
“el hombre, Orfeo caído, está condenado por una fuerza o por fuerzas desconocidas a descender en los adentros de sí mismo, enfrentar a su propia muerte en la misión de buscar las fuentes de su ser enigmático" (61); en María Eugenia Urrutia: "el poeta [...] sugiere la búsqueda en las profundidades del ser, la experimentación del poeta en un mundo sumergido, la dimensión órfica, visionaria, la indagación en el subconsciente" (19) ${ }^{3}$; en Juan Villegas-Morales: "Díaz Casanueva y Rosamel del Valle siguen acentuando [...]: la poesía como buceamiento en el mundo interior” (65); y en Guillermo Mondaca: “el trabajo poético de Rosamel del Valle se puede entender como una totalidad que tensiona la relación entre el sujeto con su exterioridad y su interioridad, estableciendo, así, viajes metafóricos hacia el macrocosmos externo y hacia el intracosmos interno, simbolizado permanentemente por la figura del descenso a las profundidades" (s/p); entre otros. Ejemplos de la segunda tendencia la encontramos en Alejandro Zambra: "el lirismo quebrado de la última poesía de Rosamel del Valle: poesía de la ciudad que, [...] proviene tanto de Baudelaire como del vagabundeo azaroso por Manhattan” (120); en Grínor Rojo, que alude a la vanguardia de una ciudad imaginada más que histórica: “¿no habrá un Rosamel que sea diferente [...]? Me refiero a la imagen de la ciudad, que está en su trabajo desde el primero hasta el último libro" (101) y, finalmente, en los estudios de las crónicas rosamelianas de Macarena Urzúa ${ }^{4}$.

\footnotetext{
${ }^{3}$ En la primera monografía crítica sobre el poeta, titulada Rosamel del Valle, poeta órfico, publicada en 1996, María Eugenia Urrutia sostiene que en el libro Poesía "la ausencia de Dios, en una época marcada por la devastación de la guerra, se perfila en una constante búsqueda de infinito, a través de modos no convencionales" (19). Agrega que la trascendencia vacua que caracteriza a la poesía moderna, según los términos del teórico alemán Hugo Friedrich, llevan al poeta chileno a una búsqueda poética a través de la vertiente órfica. A partir de estos supuestos Urrutia propone una hipótesis de lectura bastante amplia que asume la escritura rosameliana como una reflexión metapoética y "como una forma de conocimiento e investigación, tanto de aspectos del mundo exterior como de las capas profundas del ser" (19). A una conclusión más acotada llega René Olivares en su tesis de Magíster, en 2007, al sostener que en la obra Orfeo, la muerte o descenso al Hades, es la representación simbólica del viaje interior o conocimiento profundo del ser.

${ }^{4}$ Para ahondar en los aspectos de la segunda tendencia crítica, nos valemos de las reflexiones de Naín Nómez que, en su segundo tomo de la Antología crítica de la poesía chilena (en la que incluye a Rosamel del Valle), contrapone el discurso poético a los modos discursivos ejemplares del sujeto de la modernidad. Explica que incluso hay discursos poéticos críticos distintos, hasta contrapuestos, que dan cuenta de una discursividad poética multifacética en contraposición al repertorio ideológico del modo discursivo ejemplar. "El sujeto de la modernidad [sostiene] se liga primero a una concepción filosófica centrada en la razón y más tarde a la modernización del capitalismo con el incremento de la productividad en el trabajo [...]. Este sujeto de la modernidad, se articula, identifica y contradice con las posturas del sujeto poético que lo asimila en el discurso literario y que al hacerse cargo del imaginario cultural busca sus propias maneras de apropiarse de la realidad asumiéndola como totalidad contradictoria" (6). Se trata de una idea cuyas fuentes teóricas las podemos encontrar en pensadores como Matei Calinescu que en 1987 categoriza con precisión las dos
} 
En su esfuerzo crítico René Olivares reúne las dos tendencias bajo el título dual de "mito y modernidad". Una conjunción que nos permite aseverar que ambas miradas sobre la poética rosameliana, tanto la que aborda sus aspectos metafísicos o míticos como la que acentúa la contradicción con el sujeto de la modernidad, dan cuenta del afán liberador de dicha estética, y en donde la fórmula mítica no es menos efectiva para ese fin desde el momento en que se rescata una manera de captar la realidad distinta a la impuesta por el modo discursivo ejemplar y ortodoxo del sujeto moderno. Así es como Olivares postula que

la relación entre el mito y la modernidad en la obra literaria de Rosamel del Valle se refleja en la tensión entre un proyecto poético basado en una concepción mítica del mundo y de la poesía, y un contexto histórico que privilegia las posturas más racionalistas, relegando lo poético y lo mítico a una postura subalterna (Mito y modernidad...26, cursiva en texto original).

La hipótesis que propone mi investigación secunda a la primera tendencia crítica (la metafísica) e intenta descifrar el código simbólico de una muerte resignificada, ya no como un viaje al abismo interior del sujeto poético (en los términos que defienden María Eugenia Urrutia y René Olivares), sino como un mecanismo de trascendencia palingenésica de índole veladamente soteriológica, aunque menos religiosa que literaria. Un código simbólico que, en los términos del crítico Gutiérrez Girardot, admite ser calificado como un sustituto de la religión perdida ${ }^{5}$. Esta hipótesis permite ampliar el rango de las fuentes de la

modernidades: "durante la primera mitad del siglo XIX una separación irreversible tuvo lugar entre la modernidad como una etapa en la historia de la civilización occidental -producto del progreso científico y tecnológico, de la revolución industrial, de los arrolladores cambios económicos y sociales ocasionados por el capitalismo- y la modernidad como concepto estético. Desde entonces, las relaciones entre las dos modernidades han sido irreductiblemente hostiles" (55).

${ }^{5}$ Rafael Gutiérrez Girardot corrobora la secularización de la literatura moderna en cuanto representación de un mundo sin Dios. Se fundamenta esta nueva corriente de pensamiento en un positivismo que no fue simple materialismo sino la instauración de lo que Gutiérrez llama "una nueva teología intramundana" (78). Según él, la forma de la poesía mística fue invertida al ser utilizada para expresar algo profano pero aclara que la secularización "no sólo consistió en el uso de nociones y conceptos religiosos para expresar cosas mundanas y profanas, no sólo, pues, en la 'mundanización' de la vida, sino en algo más profundo que anunciaron Hegel y Jean Paul y que desde Nietzsche se conoce como 'la muerte de Dios'. No se trata del 'asesinato' de Dios, como suele interpretarse ligeramente este anuncio, sino de su 'ausencia"' (82). Se refiere, entonces, a un estado caótico en el cual el sujeto moderno pierde la certeza, no solo de un más allá, sino que es "lanzado del más allá y del más acá a sí mismo [donde] la secularización fue no solamente mundanización y sacralización simultánea del mundo y de la vida, sino también pérdida del mundo" (83-84). Esta pérdida de mundo al que 
poética rosameliana a otras obras que giran en torno al mismo dilema metafísico. La epopeya de Gilgamesh (segundo milenio a.C.), por ejemplo, perteneciente al corpus de literatura cuneiforme más antiguo de la historia de la humanidad, es un poema épico cuyo personaje homónimo (una especie de Orfeo babilónico) desciende al inframundo motivado por la angustia provocada por la muerte de su íntimo amigo Enkidu y dialoga con Utanapishti y su esposa (similares a Hades y Perséfone) para obtener, sin éxito, la fuente de la inmortalidad y el regreso a la vida de Enkidu. Al igual que el mito de Orfeo, Gilgamesh, en la primera visión de ultratumba en la historia de la literatura, desciende y asciende una sola vez desde la muerte sin perder su individualidad. Sobre la base del subtítulo de la epopeya: "el que ha visto lo profundo", este relato se ha traducido simbólicamente como un camino a la sabiduría.

Otra fuente, culturalmente relevante para la mejor comprensión de la poética de Rosamel del Valle, puede encontrarse en una de las varias historias enmarcadas que conforman el abigarrado conjunto de la novela El asno de oro (170 d.C.) de Apuleyo, en donde se narra el famoso idilio entre Cupido y Psique. En el relato, esta última se ve obligada por Venus, entre otras crueles peripecias, a descender a los abismos tártaros con un encargo para Perséfone que no alcanza a cumplir. Finalmente es rescatada de sus infortunios por Cupido y son felizmente autorizados para contraer matrimonio, obteniendo la divina inmortalidad. Dentro de un sinnúmero de esfuerzos hermenéuticos que han intentado descifrar esta fábula, el cruce del umbral de la muerte y el descenso a las simas más profundas del ser puede ser leído simbólicamente como el necesario conocimiento que requiere el alma (Psique) para llegar a su máxima cima en la eternidad del amor (Cupido) ${ }^{6}$.

El crítico chileno Hernán Castellano Girón, en un valioso intento por catalogar las fuentes literarias del autor de Orfeo, acota que "dista mucho de haberse dilucidado críticamente el ambiente precursor del arte poético rosameliano" (54) y propone una lectura de su obra bajo la ascendencia dariano-parnasiano-simbolista de un nutrido árbol de ancestros que toma como base el poema "Puerta para no pasar" de la siguiente y quinta

da lugar la secularización, permitió a la literatura, y en particular a la poesía, asumir un rol cultural protagónico en cuanto nueva mitología como "sustituto de la religión perdida" (86).

${ }^{6}$ Debido a las restricciones de espacio dejo someramente enunciados otros ejemplos afines que pueden enriquecer el entendimiento de la muerte rosameliana: desde el descenso a los infiernos en las obras de Homero y de Virgilio hasta el periplo de Dante, pasando por el décimo y último capítulo de La República, de Platón, a propósito de Er el panfilio que, habiendo resucitado, relata los juicios que ve en el más allá; un Lázaro bastante más extrovertido que el del Nuevo Testamento. 
publicación, El joven olvido (1949). En esta obra, con 17 poemas en verso, se incorpora por primera vez una dedicatoria seguida de un epígrafe. En este caso a su esposa Thérèse Dulac con quien contrae matrimonio en 1948 y que contiene los siguientes versos de Novalis: "En lo profundo del seno de la tierra, / lejos de donde la luz pueda hallarnos" (I 203). Esta dedicatoria introduce al autor dentro de las referencias órficas, y a su esposa, a quien invita a descender al Hades, distorsionando el mito con una Eurídice que, en vez de ascender con Orfeo, desciende con él a la muerte. Y el primer poema "Entrada al reino" se inicia con el verso: "me muevo y alguien se mueve detrás de mí” (I 205), invirtiendo nuevamente la secuencia de la trama del mito original (entiéndase la entrada al reino como el ingreso a la muerte, catábasis nuevamente). Con ello se complejiza mi lectura ya que el hablante vuelve a descender a la muerte, por cuarta o quinta vez dentro del íter poético del autor, pero esta vez acompañado. 'El joven olvido' no es otra cosa que una nueva denominación de la muerte: "Tú, joven olvido a quien / llamarían muerte" (I 233), con lo cual se vuelve a problematizar el tema de la memoria en el ciclo palingenésico al calificar a la muerte como un olvido. Por otra parte, las constantes referencias necro-poéticas de un hablante que emite su discurso desde la muerte como un lugar de enunciación habilitado en el texto confirman la insistencia del autor en representar al sujeto poético dentro de un mecanismo de rotación trascendente; “Oh, muerte recomenzada” explicita un verso (I 209). Asimismo, en esta entrega se amplía el espectro de referencias literarias a una serie de textos que colaboran en la dirección metafísica asumida en las publicaciones anteriores, con alusiones a Cristo: "tú querías volver a la muerte [...] latir de nuevo en la joven / eternidad prometida" (I 212); a Narciso: "«He aquí la delicia de verme pasar, seguido / de mí mismo hasta la muerte»" (I 221, comillas anguladas y cursivas en el original) y a Beatriz: "ninguna muerte más suave / para buscar tu boca" (I 250). Textos que consignan, a su vez, los mitemas ya recurrentes de la escala (de Jacob en esta ocasión), la lámpara, el viaje y la puerta. "Puerta para no pasar" se titula precisamente el último poema que consigna un amplio repertorio de precursores (renacentistas, humanistas, románticos, simbolistas y surrealistas) que culmina, decidoramente, con Walt Whitman, el autor del famoso verso vitalista: "no existe la muerte" (35), en íntima conexión con el vivífico y pitagórico verso rosameliano: "nada puede perecer" (I 238). 
La intensidad tanatológica de El joven olvido se mantiene con el mismo énfasis en la siguiente publicación, Fuegos y ceremonias (1952), que contiene 38 poemas en verso y prosa, con títulos explícitos como "Orfeo en la ciudad más irreal” o "La muerte mágica”. A los recurrentes mitemas rosamelianos, se agregan el hilo invisible, el sueño y las varias muertes que, al complementarse con los anteriores, amplían el espectro simbólico de esa estética oscura. Las llaves de las puertas son reemplazadas en esta publicación por el hilo que conecta los mundos de la vida y la muerte: "No vivirás sino seguido del hilo invisible que es el portador sin fatiga del único mensaje del mundo apenas entrevisto. No verás vivir sin morir [...] No olvides, es el hilo que te atraviesa el corazón cuando despiertas" (I 294, cursivas en el texto original). Entre la muerte y la vida hay una conexión intangible que las torna inseparables; ese hilo que traemos al nacer y que continúa con nosotros al morir: "con este ardor he abierto la vida de par en par / para hacer que este cuerpo solo pase por el mundo / como el hilo por el ojo de la aguja" (I 299). Y en otro poema se insiste: "«por un hilo de vidrio / vuelve el hombre a la tierra» [...] Después de la décima puerta viene la primera" (I 305-306, comillas anguladas en texto original). Es el hilo que conecta las sucesivas catábasis y anábasis -“subí y descendí”- (I 328), y que transforman al hablante en un sujeto poético escatológico: "la vida que no viene sino de lo que perece" (I 286). Por otra parte, el símbolo del sueño, que supone la alternancia de dormir y despertar sucesiva e indefinidamente, conlleva un ritmo circulatorio que le acomoda al hablante para representar analógicamente la idea cíclica de un constante morir y renacer -“a menudo me acuesto pensando en una metamorfosis", nos dice- (I 312). En este sentido el mitema del viajero metafísico es combinado con el del sonámbulo (I 298), con el del lamparero que se duerme (I 305) y con el del gusano tornasol (I 332). Cuando "el sonámbulo despierta al compás de las raíces" (I 327), estamos ante el hablante que regresa a la vida desde lo obscuro y a su diario despertar se le designa como la "resurrección de cada noche" (I 309). En otro poema se lee una idea similar: "así canta / mientras duerme el gusano tornasol [...] y el gusano celebra la resurrección” (I 332). Y en una alocución notoriamente palingenésica, el verso "retornar es morir" (I 321) admite leerse en comunión con el siguiente extracto del poema “Celebración”:

[...] Luego

Los descensos profundos al imán de los sueños 
Donde todo está escrito. Donde los jóvenes monstruos

Celebran el ritual de la húmeda muerte con un cántico

Dedicado al invierno. Y el regreso. El regreso por escalas

Parecidas a la respiración del que duerme. El regreso

Hacia el festival terrestre, con el corazón abierto

A una primavera recién nacida (I 327).

Si retornar es, a la vez, morir y nacer, el discurso poético está modificando la carga semántica de términos convencionalmente antitéticos y generando una resemantización ostensible de la muerte que, según mi hipótesis de trascendencia palingenésica, da cuenta de una necro-poética aparente, ya que augura una cosmovisión vitalista, que al final nos induce a pensar en la inexistencia de la muerte, especialmente cuando se nos dice que "para resplandecer hay que morir" (I 272), que "mirar es morir un poco" (I 277) o que "la muerte es regocijo" (I 309). En definitiva, los dos últimos poemarios recién comentados contienen un intenso y paradójico temple vitalista de la muerte cuando se cierran ambos conjuntos con un profético último verso. En El joven olvido: "la muerte cantaba afuera en el árbol de la mañana" (I 258) y en Fuegos y ceremonias: "mientras la muerte dice: Hasta mañana" (I 334, cursiva en original).

Esta continuidad cíclica es lo que explica los dichos de Humberto Díaz Casanueva cuando comenta Fuegos y ceremonias: "[m]ás que leerle fortuitamente un poema o dejarnos deslumbrar por fragmentos erizados de relámpagos, debemos apreciar la totalidad de la obra, las grandes líneas de su concepción central y el ahondamiento dramático de sus motivos" (138-139), dichos que respaldan una de las conclusiones que se aventuran en esta investigación sobre la base de una lectura diacrónica y que percibe la configuración de un opus escatológico rosameliano. Esa misma continuidad cíclica, entonces, es la que nos conecta con el siguiente eslabón de esta poco comprendida progresión metafísica del discurso rosameliano: La visión comunicable (1954), con 27 poemas en verso que profundiza el mitema de las varias muertes esbozado en la obra anterior. Si en los inicios de Mirador (1926) el hablante sólo miraba o columbraba, 28 años después está habilitado para compartir su visión, definitivamente empoderado del proceso palingenésico. Fuegos y ceremonias termina con la muerte que repite insistentemente "hasta mañana", lo que confirma un proceso de anábasis que es retomado pendularmente como catábasis en "Mano tornasol”, el primer poema de La visión comunicable: “[y] ha muerto el viajero alucinado 
por las llamas [...] pero viven y cantan / los gestos y las palabras olvidadas en una colina / en el día que en vano trato de recordar y que es / mi propia resurrección postergada" (II 10). Idea que es reforzada después en el mismo poema: "himno de muertos en subida y bajada". El mitema de las varias muertes y sus consecuentes varias vidas se constituye en el tópico central de esta obra a través de innumerables procesos de rotación metafísica que completan el ideario palingenésico de la cosmovisión rosameliana, y que se confirma en gran parte de sus poemas. Después de la catábasis del primer poema, y desde "Sala de espera" hasta "En el corazón duerme una abeja", el hablante queda esperando la anábasis que luego se concreta en "Signos". A continuación, en "Segundo canto de amor para el corazón" retorna la catábasis y se produce, incluso, una aceleración del mecanismo cíclico cuando ambos procesos de anábasis y catábasis están representados dentro del mismo poema como en "Los regresos” y "Cánticos de la visitación”. El proceso continúa entre los poemas como una especie de respiración esotérica: "Eurídice es la estrella olvidada" y "De hora en hora a de hora en hora" (catábasis); "Algunos torbellinos" y "Otros desastres" (anábasis), y "Llama familiar" (catábasis). En verdad que a esta altura del itinerario poético rosameliano se puede afirmar que estos procesos nos evocan la respiración de un mecanismo superior al que el hablante está supeditado, sístole y diástole de un fuelle metafísico. Una obra poética que inhala y exhala.

Decía al inicio de este trabajo que mi intención era demostrar la cercanía entre la poética escatológica rosameliana y las diversas creencias palingenésicas con el afán de sustentar mi hipótesis de lectura. Las doctrinas órfico-pitagóricas que vimos al principio son el correlato griego de la doctrina hindú contenida en los Upanishad (siglo IX al V a.C.). Este corpus hinduista sagrado está compuesto por más de 200 libros escritos en sánscrito y según su creencia, aquel que tiene deseos muere para volver a nacer en un mecanismo rotativo que se mantendrá cíclicamente mientras dure dicho deseo. Cuando el deseo desaparece se muere por última vez ya que se detiene la sucesión de nacimientos y el sujeto se libera de este encadenamiento para disolver su individualidad en la totalidad de Brahma. Se distinguen en esta creencia, entonces, dos etapas importantes para este trabajo: la primera es el circuito de rotación metafísica, semejante a los procesos de catábasis y anábasis representados en la poesía de Rosamel del Valle; y una segunda etapa, de la cual 
se aleja la estética rosameliana, en la que la individualidad del sujeto se disuelve, a través de un giro panteísta, en la totalidad de Brahma $^{7}$.

Así como en la teogonía órfica los ciclos de renacimientos conducen a la purificación y al reingreso en el alma universal, y en la teogonía brahmánica los ciclos conducen a la liberación y el regreso a Brahma, en la trascendencia palingenésica rosameliana, en cambio, el sujeto se mantiene indefinidamente en el mecanismo de rotación metafísica. Esta paulatina e irreversible anulación de la muerte en el texto poético conlleva, finalmente, una transcodificación semántica de la vida al anulársele el opuesto en su relación antitética.

Los últimos libros publicados en vida del autor (El corazón escrito, 1960 y El sol es un pájaro cautivo en el reloj, 1963) continúan representando con mayor o menor intensidad los mecanismos de catábasis y anábasis y se ratifican tanto los postulados estéticos como los mitemas hasta aquí desarrollados. Y el póstumo Adiós enigma tornasol (1967), cuyo título alude a una posible despedida del hablante, desliza veladamente cierto escepticismo a la trascendencia palingenésica impregnada en su obra y un inédito acercamiento a la nomenclatura cristiana de la resurrección (mencionada diez veces en los doce poemas del conjunto), sin que por ello se desconfigure necesariamente la estructura estética de su opus poético que postula una recodificación semántica de la muerte.

En conclusión, el hablante rosameliano, en cuanto sujeto escatológico, emite su discurso desde dos lugares contrapuestos de enunciación: desde la vida, desde la muerte e incluso en el tránsito entre ambas, sometiendo al lenguaje a los requerimientos que sólo la poesía es capaz de soportar. El significado de las palabras asignado en la vida muta cuando se traslada a la muerte; se produce una alteración semántica que dificulta la comunicación del hablante, y el discurso termina estructurándose sobre la base de símbolos que apenas pueden columbrarse. Estamos, en definitiva, ante un mecanismo que pretende desquiciar el signo mediante el abuso arbitrario de la forma, con el objetivo estético de representar la ficticia adecuación léxica que supone el paso del discurso poético desde una dimensión vital a otra mortal. La colonización lingüística de la muerte, que se esconde dentro de su inefable invisibilidad, proyecta la tonalidad optimista, antes anunciada, de una poética que

\footnotetext{
${ }^{7}$ Para este trabajo he optado por la fuente clásica, la traducción del filólogo alemán Max Müller (The Sacred Books of the East, 1895).
} 
representa a la vida absorbiendo semánticamente a la muerte en el continuum de eternidad que genera la perpetua rotación metafísica de la catábasis y anábasis. Empero, no se trata de un discurso religioso que propugna la fe en una trascendencia post mortem sino de una propuesta estética que modifica nuestra percepción de la realidad cuando nos conduce, finalmente, a imaginar la remota posibilidad de que la muerte no exista.

\section{BIBLIOGRAFÍA}

Apuleyo. El asno de oro. Madrid: Ediciones Cátedra, 2008.

Bernabé, Alberto. Fragmentos presocráticos. De Tales a Demócrito. Madrid: Alianza Editorial, 2008.

Calinescu, Matei. Cinco caras de la modernidad. Modernismo, vanguardia, decadencia, kitsch, postmodernismo. Madrid: Alianza Editorial, 2016.

Castellano-Girón, Hernán. "Fuentes de la poética de Rosamel del Valle: la línea simbolista surrealista". Revista Atenea 473, 1996: 53-69.

Del Valle, Rosamel. Obra poética. 2 tomos. Santiago: J.C. Sáez Editor, 2000.

Díaz Casanueva, Humberto. "Los libros: Fuegos y ceremonias, último libro de Rosamel del Valle". Revista Atenea 339-440, 1953: 138-146.

Ferrater, José. Diccionario de filosofía. Buenos Aires: Editorial Sudamericana, 1951.

Gutiérrez-Girardot, Rafael. Modernismo. Supuestos históricos y culturales. Bogotá: Fondo de Cultura Económica, 2004.

Jankélévitch, Vladimir. La muerte. Valencia, España: Pre-textos Ediciones, 2002.

La epopeya de Gilgamesh. Barcelona: Random House Mondadori, 2004.

Los Upanishad. Barcelona: Ediciones Brontes, 2008.

Mondaca, Guillermo: "Rosamel del Valle: viaje tornasol". Revista electrónica letras.mysite.com. Web. enero de 2020 http://letras.mysite.com/gmon180814.html.

Nómez, Naín. Antología crítica de la poesía chilena, Tomo II. Santiago: LOM Ediciones, 2000.

Olivares, René. La apropiación del mito de Orfeo en Rainer María Rilke y Rosamel del Valle en los textos Sonetos a Orfeo y Orfeo. Tesis para optar al grado académico de Magíster en Literatura. Santiago: Universidad de Chile, 2007.

. Mito y modernidad en la obra de Rosamel del Valle. Postdam: Universitätsverlag Postdam, 2016.

Ovidio. Metamorfosis. Madrid: Editorial Espasa Calpe S.A., 2008.

Platón. Diálogos socráticos. México: Editorial Océano, 1999.

Rojo, Grínor. "El regreso de Rosamel del Valle". Revista Chilena de Literatura 59, 2001: 99-109. 
Schweitzer, S. Alan. "Rosamel del Valle: poeta órfico". Revista de Estudios Hispánicos VII 1 (1973): 61-77.

Urrutia, María Eugenia. Rosamel del Valle, poeta órfico. Santiago: RIL Ltda., 1996. . “Análisis de 'La estación de los peces' de Rosamel del Valle". Revista Estudios Filológicos 32 (1997): 83-91.

Villegas-Morales, Juan. Estudios sobre poesía chilena. Santiago: Editorial Nascimento, 1980.

Whitman, Walt. Hojas de hierba. Barcelona: Lumen, 1997.

Zambra, Alejandro. "Rosamel ida y vuelta". Revista Cormorán 2, (2001): 119-126.

Zambrano, María. Madre España. Homenaje de los poetas chilenos. Santiago: Panorama, 1937. 